\title{
Mixed Learning Styles: A Strategy for Team formation
}

\author{
Javeed Kittur $^{1}$, Minal Salunke ${ }^{2}$ \\ ${ }^{1}$ Engineering Education Systems and Design, Arizona State University, Mesa 85212, USA \\ ${ }^{2}$ Electical \& Electronics Engineering, KLE Technological University, Vidyanagar, Hubballi - 580031, India \\ jjkittur@asu.edu \\ ${ }^{2}$ minal@kletech.ac.in
}

\begin{abstract}
The emphasis of this work is to analyse and assess a cohort of students' perspectives on team learning practices in activity-based learning approach. This activity was implemented in Linear Control Systems course. The motivation for this work is the authors' experience in teaching the course in previous iteration. It was observed that some teams performed exceedingly well, and a few others struggled to complete the activity. We believe that the reason for this was that the team formation was random. Team learning emphasizes interaction between students 'through peer-to-peer learning, which strengthens the ability of a student to solve problems better. The authors felt there is an opportunity to explore the following research question: Does working in teams formed with mixed learning styles enhance student learning? In order to form teams, students underwent Index of Learning Styles Questionnaire by Richard M. Felder and Barbara A. Soloman. A common problem statement on modified Load-Frequency control model of an isolated power system area, to be operated with a controller was given student teams. Section-A comprised of 16 teams and Section-B had 13 teams, each team involving members with different learning styles. A pre-test and post-test were conducted to know the change in conceptual understanding. The post-test results indicate improvement in conceptual understanding. This is also validated by the ANOVA test with a 5\% level of significance. From this study, it is observed that, strategic team formation is considered as a favourable approach for augmenting students' learning.
\end{abstract}

Keywords: Learning styles, team formation, simulation, student learning, control systems

\section{Introduction}

In the department of Electrical \& Electronics Engineering at our university, students work in teams to complete a project, assignment or homework. The students' team formation is done by either of the following approaches; instructor assigns teams randomly or instructor assigns teams as per students' registered roll numbers serially or students select

\author{
Javeed Kittur \\ Engineering Education Systems and Design, ASU, USA \\ jkittur@asu.edu
}

their own teammates or students continue as a team who are already working for a project or students self-select teams based on a topic. These strategies used in forming teams show huge variations in students' learning, performance, and scores across teams. There could be different reasons for this issue such as students are overlooked or rejected, inequity in skill and task distribution, students' concern about the skills and attitudes of other students [1]. The other reason for this issue could be the lack of a strategic approach in forming teams for completion of a task [2]. Literature on team formation suggests strategies for team formation and the implications of these strategies [1][2][3][4].

The authors' experience in the past with respect to team formation has been infrequently good because only a few teams meet the set expectations and most teams fail to reach the target. With this as the motivation, the authors felt there is an opportunity to explore the following research question: Does working in teams formed with mixed learning styles enhance student learning? In order to address this quantitative research question, a core course in electrical and electronics engineering curriculum is considered titled as 'Linear Control Systems' for experimentation.

A linear control systems course is one in which students come across difficulties connecting the theoretical concepts taught in class to the real world. One of the reasons could be that everything from the basic controller design to a sophisticated control system involves mathematical concepts. All these concepts form the basics or the prerequisites to analyse a system. The early lessons in the control systems course involve high content of mathematical concepts and this requires a lot of imagination to understand the concepts thoroughly. We believe that this is when the students' motivation starts to decline from the course. Hence, it is essential to use simulation tools which will allow students to practice and study the behaviour of the system by varying different parameters, the same is echoed in [5]. In this study, student teams are formed to complete a simulation assignment and mixed learning styles are used as a strategy to form teams to work on the assignment in the course. We expect that this activity will provide an opportunity to explore the research question: Does working in 
teams formed with mixed learning styles enhance students' learning?

This article is organized as follows: following introduction is the section on the significance of team work. The subsequent section provides details of team formation strategy using learning styles. The next sections focus on method, findings, discussion of findings and observations.

\section{Why Teams?}

Gaining proficiency in just the technical aspects of a field is not enough anymore. Employers are looking for engineering graduates with professional skills such as communication and the ability to function well in a team by the time they join the workforce. In order to make the students ready to take up the engineering tasks after their graduation, engineering programs are providing students the opportunity to work in team assignments/projects, prepare presentations and produce good quality professional reports [6].Promoting team-based learning has shown very good improvement in the end semester exam in comparison with the previous year's performance scores [7]. Considerable literature supports the claim that working in a team contributes to the enhancement of student learning [8][9][10][11].

This section deals with the significance of team formation and its impact on the students' learning experience. To comprehend this impact, it is important to first understand what makes a successful team work. The subsequent subsections discuss the successful collaboration and group selection options.

\section{A. Successful Collaboration}

The learning experience in a team is considered as a beneficial approach for improving the learning of students in a collaborative environment. This experience engages student interactions and promotes learning through peers thereby enabling students with different skills such as problem-solving, leadership, communication; etc [12]. The collaborative learning environment is beneficial for students in several ways. Firstly, the collaborative environment ensures the learners' engagement in the subject and this will, in turn, facilitate knowledge retention [13]. Secondly, the greater than before exposure and socialization to varied ideas increases the students' involvement in the task to be accomplished [14]. Finally, there is cognitive development in the learner in the collaborative environment due to the heavy processing of the information [13].To provide an opportunity for collaborative experiential learning to reinforce the theoretical concepts imbibed in students the authors follow model on collaborative experiential learning which concentrates on the beginning of instruction referring to Fink's Model containing Knowledge of subject matter, Design of Course, Teacher-student interaction and Course management [24].

The benefits stated above hold good only if there is interaction among the team members [2]. In this study, there is huge scope for student interactions as the task to be accomplished (assignment) is an out of class activity. The time allotted for completing this activity is comfortable and motivating the learners to have multiple interactions with their respective team members and other team members as well pertaining to the topic of the assignment. The conversations of the team members could be in the form of questions, suggestions, idea explanations, convincing the members of an approach to be solving the problem, etc. It is difficult for the instructor alone to monitor the quality of interactions/conversations in all the teams, however, what type of conversations should a team have could be moderated by the instructor using a structured approach. The moderation of interactions in this study is done during the reviews for the assignment.

\section{B. Group Selection Options}

There are different ways of selecting the members of a team depending on what is the focus of the activity and what expectations need to be met. A couple of the possible group selection options are highlighted in this section and the details presented on this topic are largely taken from the reference [1].

Student self-selection is one of the easiest methods of team formation; this method does not follow any criteria apart from the students' choice to form teams. The advantage of this method is that students get to choose members with whom they want to work with. The concerns with this method are; few students may be ignored or left out, the team members may have inequality in terms of skills and hence the tasks to be accomplished [1][2].

Random selection is another method used in forming teams; this method also does not follow any criteria. The advantage of this method is that it provides students the opportunity to interact and learn from the new members and hence improve their communication skills. The concerns associated with this method are; students may dislike that they did not have the choice to select team members and the student would be concerned about the skills and attitudes of other team members [1].

Another team formation method is a selection of team members based on topic choices. The advantage of this method is that students get to work on a topic of their interest along with other members of the team with same interest. The concerns associated with this method are again the inequality in terms of skills and hence the tasks to be accomplished and student would be concerned about the skills and attitudes of other team members [1].

The selective appointment is one more team formation method which uses criteria in selecting the team members. The advantages of this method are that students have familiar goals, the low performers are under less pressure comparatively, student's get rewarded for exhibiting their skills and there exists diversity in the group. This method also has concerns such as; very little is expected from the low performers and hence they end up doing mundane work gaining no specific skills, less chance for newer skills development in new roles and team members with common goals may not accept the other members of the team [1][4].

Grouping students for an activity, requires serious attention as it will impact the students' learning considerably 
[2]. There are different strategies used for team formation but learning styles have become one of the most common approaches used to group students to make them function effectively in a collaborative environment [1][2][12]. Referring to the enormous advantages of learning styles in the literature, the authors have used mixed learning styles approach in forming teams for the concerned activity to be implemented. The next section presents details about the various learning styles and how to acquire these styles of students.

\section{Simulation as a basic tool for learning}

Engineers in the real world must look beyond the theoretical aspects of a concept as it requires practical knowledge in complementary with the theoretical background to propose a solution for a real-time problem [16]. In engineering education, we come across two different learning environments, classroom, and laboratory. As per the authors, past experiences most of the classroom learning is focused on passing the information on theoretical foundations of different concepts and laboratory facilitates experiments to be conducted only on a few sets of concepts. With this as a background, there is a need for some platform wherein students may get an opportunity to experience the practical aspects of most of the concepts presented in class.

A simulationwhich is one of the most significant aspects in the field of Internet-based educational environments could serve as a platform to help reinforce concepts [5]. Simulation-based environments help students with opportunities of experiencing the simulated system or world. In order to solve a real-world problem, it is better to simulate it first and test for all possible conditions and then implement it practically [5]. Structured learning experiences could be designed through simulation-based learning activities and the same is echoed in [17], however, the focus of [17] is on medical education. In a study conducted in the course linear control systems, the students have preferred simulationbased assignments over the typical writing assignments and quizzes [7].

Simulation environments help learners to understand the concepts better by extracting knowledge in the process of completion of a task. If the task is an assignment it will help the learners to discriminate between different variables, the hypotheses, and interpretation of the experimental results [18].The effectiveness of using modern engineering tool was presented to enhance the learning in fundamental course of electrical engineering as simulation tool plays an important role within the frame of teaching and learning in education across the world [25].

In control systems engineering, simulation is one of the important parameters for enhancing students' learning. Using simulations students get the liberty of verifying the concepts studied theoretically by conducting any set of experiments with varied sets of data. Students may also compare the results of experimentation for a better understanding of the concepts [19].

\section{Felder-Soloman Index of Learning Styles}

Every person has a preferred style of learning. It guides and encourages an individual to enhance the personal approach to information. It will establish a frame for learning strategies to an individual which could function better for his/her learning.

The Index of Learning Styles (ILS) developed by FelderSoloman is a self-scoring web-based instrument that assesses preferences in eight areas using four contrasting scales. The instrument is freely available from the author's website, which also contains data from groups covering a wide range of disciplines [15]. The ILS has four scales of learning style preferences ranging from 1 (slight) to 11 (strong). Negative values $(-1,-3,-5,-7,-11)$ is assigned to the left part of the scale whereas positive values $(1,3,5,7,11)$ is assigned to the right. part of the scale. The range on the scale is sectioned into 3 bands: a band which ranges between 3 to -3 , range between -5 to- 7 and 5to 7 and range between -9to-11 and 9to 11 [15]. In order to model the student learning style, ILS developed by Felder-Soloman was used.

Table 1- ILS Scales

\begin{tabular}{|c|c|c|}
\hline Scale & $\begin{array}{c}\text { Negative } \\
\text { Polarity }\end{array}$ & $\begin{array}{c}\text { Positive } \\
\text { Polarity }\end{array}$ \\
\hline Active-Reflective (AR) & Active & Reflective \\
\hline Sensing - Intuitive (SI) & Sensing & Intuitive \\
\hline Visual-Verbal (VV) & Visual & Verbal \\
\hline Sequential - Global (SG) & Sequential & Global \\
\hline
\end{tabular}

\section{Case study}

The main aim of this study is to examine the impact of mixed learning styles on the success of team work and individual learning. To address this concern a case study is designed, and the following subsections present the details on the same.

\section{A. Goals}

One of the main goals of this study is to find out whether the learning styles of students' functioning collectively influence the outcome of the team work. If so, the authors would like to further examine to find what parameters affect the success of students learning experiences. Specifically, the study is focused on finding the change in students' learning when they are made to collaborate with members having different learning styles (using the mixed-learning styles approach). The study tries to address the following questions;

- Does the performance of students when working collaboratively depend on learning styles?

- In alignment with the outcome of the activity is there any element of learning styles which is more significant than others?

\section{B. Assumptions}

The assumptions that encouraged in designing this case study are the past experiences of the authors and the various dimensions of the topic under study in the literature. In the past the authors have formed students' teams without strategy and/or with a strategy which followed a vague approach without any theoretical backing or support to the 
strategy used. The outcomes of the collaborative work of such teams for a given task did not meet the expectations and most students encountered difficulties in completing the assigned task. So, the authors felt there is scope for exploring the strategy of using learning styles of students and forming teams accordingly to maximize students learning.

A team must include members who can bring about distinct perspectives as this would impact the collaborative task and this is possible with varied learning styles [20]. In a collaborative work, some elements of the learning styles propose greater effect than the other elements. As per Felder and Silverman [21], the active and the reflective elements of learning styles have greater chances of influencing the collaborative outcomes. The strategy of mixed learning styles has been implemented and this paper documents the obtained results for one course in Electrical \& Electronics Engineering discipline. The subsequent section discusses the various elements of learning styles.

\section{Results}

The following subsections show the results obtained from the case study. It includes details on data analysis obtained from the ILS score and validating through statistical analysis, how the team is formed based on the outcome of data analysed, the setting-up of case study and pre-test and posttest attainment.

\section{Data Analysis}

Scores from the ILS instrument were collected from students of two sections A \& B of 2nd-year Electrical and Electronics Engineering program registered for control systems core course. This study only analyses the total scores for each scale reported by an online assessment instrument [15]. As a sample the distribution of AR scores from each group by scale is depicted in Fig.1.

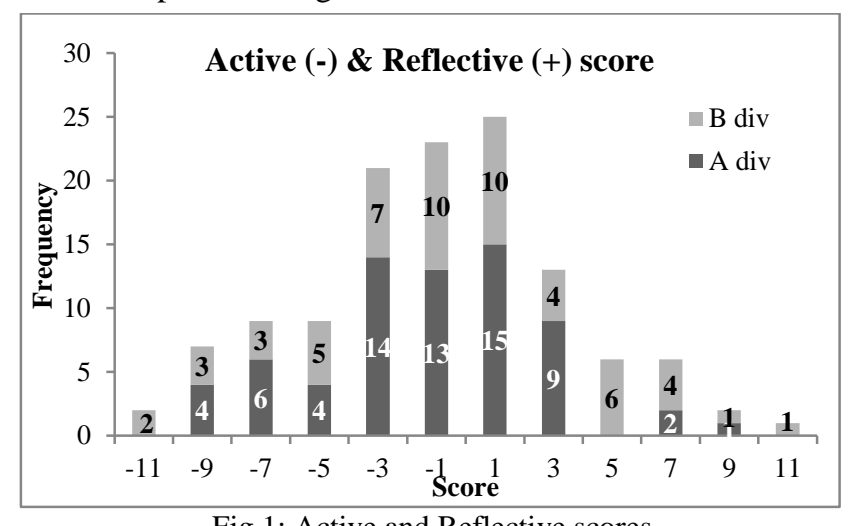

Fig.1: Active and Reflective scores

From Fig. 1 it is observed that 51 students' score from A section lie in the band of 1-3 which means they are fairly well balanced between active and reflective learning style. Whereas, about 30 students' score from section B lies in the band of 1-3. It was also observed that 47 students' score from A section lie in the band of 1-3 which means they are fairly well balanced between Sensing and Intuitive learning style.

Table 2 shows the results of different learning styles. From the category of AR learning style, $75 \%$ students of A section know if we always act before reflecting, we can jump into things prematurely and get into trouble, while if we spend too much time reflecting, we may never get anything done [22][23]. So, these $75 \%$ students are active sometimes and reflective sometimes. Whereas $50 \%$ students of B section scores are spread across whose preference is either moderate or strong for any one dimension of learning style.

In the category of SI learning style, $68 \%$ students of $\mathrm{A}$ section know if you overemphasize intuition, we may miss important details or make careless mistakes in calculations; if you overemphasize sensing, we may be dependent too much on memorization and acquainted methods and not focus enough on understanding and innovative thinking. [22][23]. So, these 68\% students are both learner and problem solvers. Whereas, it is observed that the students learning preference in B section are uniform in all the bands.

Table 2- Scores of Learning Styles

\begin{tabular}{|c|c|c|c|c|}
\hline \multirow{2}{*}{$\begin{array}{c}\text { Learning } \\
\text { Style }\end{array}$} & \multirow{2}{*}{ Section } & \multicolumn{3}{|c|}{ Learning Preference in percentage } \\
\cline { 3 - 5 } & & $\begin{array}{c}\text { Well } \\
\text { Balanced }\end{array}$ & $\begin{array}{c}\text { Moderate } \\
\text { Preference }\end{array}$ & $\begin{array}{c}\text { Strong } \\
\text { Preference }\end{array}$ \\
\hline $\begin{array}{c}\text { Active- } \\
\text { Reflective }\end{array}$ & $\mathrm{A}$ & 75 & 18 & 7 \\
\cline { 2 - 5 } $\begin{array}{c}\text { Sensing - } \\
\text { Intuitive }\end{array}$ & $\mathrm{B}$ & 55 & 32 & 13 \\
\hline & $\mathrm{A}$ & 68 & 29 & 3 \\
\hline $\begin{array}{c}\text { Visual- } \\
\text { Verbal }\end{array}$ & $\mathrm{A}$ & 34 & 28 & 38 \\
\cline { 2 - 5 } & $\mathrm{B}$ & 35 & 34 & 31 \\
\hline Sequential & $\mathrm{A}$ & 80 & 20 & 0 \\
\cline { 2 - 5 }- Global & $\mathrm{B}$ & 41 & 26 & 33 \\
\hline
\end{tabular}

Considering category of VV learning style, students learning preference are almost uniform in all the bands in section A. Although there is even distribution of learning preferences, 21 students are strong visual learners. Whereas, $50 \%$ of the class strength learning preference is moderate in section B. These students also prefer visual learning than verbal. Students with these learning preferences in both the sections prefer sketches, diagrams, flow charts, images or any other type of visual representation than the material which is verbal.

Finally, in the category of SG, $80 \%$ of students' score from A section lie in the band of 1-3 which means they are fairly well balanced between sequential and global learning styles. These $80 \%$ students are sequential learners who are well acquainted with specific aspects of the subject as well as they are good at relating them to different aspects of the same subject or with different subjects [22][23]. Whereas, students learning preference are almost uniform in all the bands section B. There are no students in A section whose learning style is strongly sequential or strongly global whereas, around 17 students of B section are strong sequential learners. These 17 students intend to follow logical stepwise paths in finding solutions, but these set of students struggle hard to solve complex problems quickly. About $15 \%$ students of both $\mathrm{A}$ and $\mathrm{B}$ sections are strong sequential learners who gain understanding in linear steps, with each step following logically from the previous one. 


\section{Statistical Analysis}

Statistical analysis was performed for each dimension of learning style to test the following two hypotheses:

1. Students from A section and B-section have different learning styles due to their previous educational background.

2. Strategically forming teams using mixed learning styles enhance students learning.

The mean and variance for each group's scores on the four scales were determined and a single factor ANOVA was used to determine if significant differences existed. The results appear in Table 3.

\begin{tabular}{|c|c|c|c|}
\hline \multirow{2}{*}{$\begin{array}{c}\text { No. of Pre and Post } \\
\text { test questions }\end{array}$} & $\begin{array}{c}\text { Blooms } \\
\text { Level (\%) }\end{array}$ & \multicolumn{2}{|c|}{ Attainment (\%) } \\
\cline { 3 - 4 } & Pre-test & Post-test \\
\hline $2(1,3)$ & L1-18.18 & 68.0 & 78.00 \\
\hline $3(2,5,9)$ & L2-27.27 & 45.67 & 54.00 \\
\hline $6(4,6,7,8,10,11)$ & L3-54.55 & 45.50 & 50.33 \\
\hline
\end{tabular}

Both sections students exhibit a slight preference for active over reflective learning with no significant difference between the mean preference $(p=0.599)$. Each of the section students in the sample exhibited a preference for learning through sensing rather than intuition. There is no statistically significant difference between group means $(\mathrm{p}=0.570)$. There is no significant difference between the group means $(\mathrm{p}=0.680)$ for visual and verbal learning styles. More number of students are inclined towards learning by seeing. Each section, on an average, exhibited a slight preference for learning through sequential rather than global presentation methods. Once again there is no statistically significant difference between group means $(p=0.725)$.

\section{E. Team Formation}

The data from previous section is used to form teams strategically. For successful completion of assignment, the necessity for a team to be formed is to have at least one student each with a well-balanced preference of active/reflective and visual/verbal learning styles respectively. The remaining members of the team could be from any other learning style preference. The teams are formed such that the maximum number of students in a team does not exceed four. The literature says that the optimal size for a team is four, however; the team size majorly depends on the scope of the tasks in a project [1]. With the above requirement, 16 teams in $\mathrm{A}$ section and 14 teams in $\mathrm{B}$ section were formed with four members per team with an exception for one or two teams with 5 members.

\section{F. Case Study Set Up}

This study has been conducted for 121 students undergoing the course Linear Control Systems. This is a 3 credits core course offered at fourth semester and it is mandatory that all students take up this course in Electrical \& Electronics Engineering program. The contents of this course include open and closed-loop control systems, transfer function models, time response specifications, frequency response analysis, stability analysis, root locus diagram, Bode plots, and controller design.
In order to determine the learning styles of each student, they were asked to complete the questionnaire for ILS. Students took this questionnaire a week before the start of the activity and the results from the questionnaire have been submitted through Google forms. The data obtained from the Google forms has been sorted and used for team formation. Special care has been taken during the team formation to have varied learning styles (mixed learning styles) in each team. Before the formation of teams, a pre-test was conducted to know the understanding levels of concepts of all the students individually. The pre-test essentially consisted of ten multiple choice questions focusing on the concepts pertaining to the assignment topic. The pre-test was conducted online using Google forms. The announcement of team members and the assignment questions have been done simultaneously. The assignment question has been shown in Appendix A. Table 4 below depicts the blooms level for each question and total attainment achieved by students.

Table 4-Blooms Level for Test Questionnaire

The students solved the assignment questions manually as a team first and during same week students were introduced to basic features of the Matlab simulation tool enough to complete the assignment activity. Students then spent one week's time to complete the simulation and verify the results obtained manually. The next step is to document all the steps followed in the assignment activity and submit a report. Three reviews have been conducted, one after the manual calculation step, the second review after the completion of simulation and final review with a report including all the artefacts of the assignment. The attainments of pre and post tests are shown in Fig.9. It is apparent that the post-test scores are improved in comparison with a pre-test. ANOVA test was performed on these tests in order to validate the significance. It is evident from results that there is no statistically significant difference between group means $(\mathrm{p}=0.387)$.

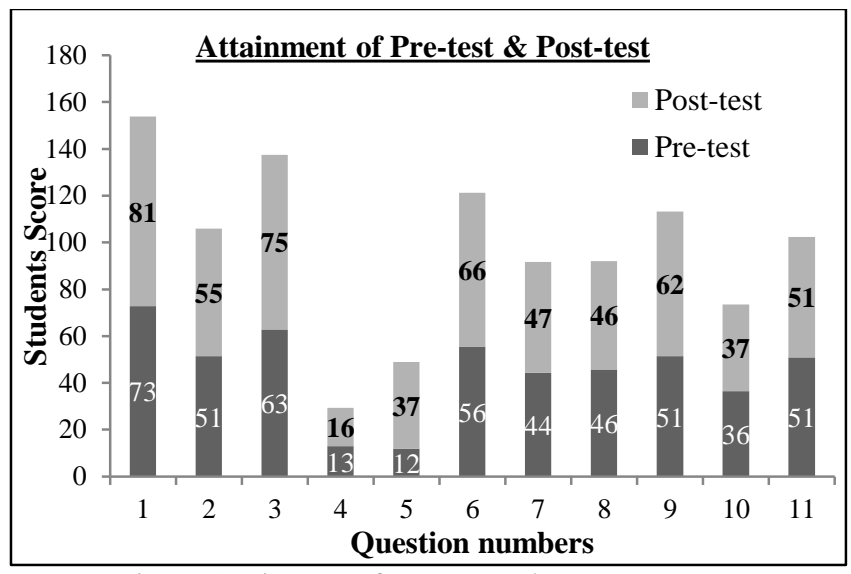

Fig. 9: Attainment of Pre-test and Post-test scores

This is a preliminary study hence the authors present only observations. From this study, the authors make the following observations; the learning styles impact the performance of both the team and the individual, this is evident from the pre-test and post-test scores. The 
team has at least one member with the learning style preferences active/reflective and visual/verbal learners, it is observed that this strategy has positively impacted the learning of students.

\section{Results}

To realize the impact of learning happened through the assignment, the written examination was conducted. Minor 2 exam is the internal assessment examination, was conducted before the activity. The semester end examination (SEE) was conducted after successful completion of the activity. The results of minor 2 and SEE examinations are shown in table 5.

The Q1b in minor2 exam and Q4b in SEE were on the topic of controller design for specific electrical application using standard tuning approach. From the data obtained it is evident that in year 2016-17, the results are improved in SEE wherein the students did not undergo strategic team formation process. On the contrary, though the results obtained in SEE for year 2017-18 has dipped by $10 \%$, the number of students' attempt has improved in 2017-18 batch. The Q2b in minor2 exam and Q5b in SEE were on the topic of controller design and deciding on stability of certain plant given for study. In both academic years the results are inferior in SEE compared to minor2. The number of students attempt has improved has also fallen in 2017-18 batch. The Q3b in minor2 exam and Q6b in SEE were on the topic of designing specific controller for specific electrical application using standard tuning approach and discussing on stability of the system.

Table 3 - Means, Variances and ANOVA results

\begin{tabular}{|c|c|c|c|c|c|c|c|c|}
\hline Section & Mean (AR) & Var (AR) & Mean (SI) & Var (SI) & Mean (VV) & Var (VV) & Mean (SG) & Var (SG) \\
\hline A & 5.67 & 32.61 & 5.75 & 24.75 & 5.67 & 40.06 & 5.58 & 41.72 \\
\hline B & 4.67 & 9.52 & 4.67 & 17.70 & 4.75 & 17.66 & 4.83 & 11.42 \\
\hline P-value & \multicolumn{2}{|c|}{0.599} & \multicolumn{2}{|c|}{0.570} & \multicolumn{2}{c|}{0.680} & 0.175 & 0.725 \\
\hline F & 0.285 & \multicolumn{2}{|c|}{0.332} & \multicolumn{2}{c|}{0.175} \\
\hline Frritical & \multicolumn{2}{|c|}{4.301} & \multicolumn{2}{|c|}{4.301} & 4.301 \\
\hline
\end{tabular}

Table 5-Results of Minor exam and SEE

\begin{tabular}{|c|c|c|c|c|c|c|c|c|c|c|c|c|}
\hline \multirow{3}{*}{ Year } & \multicolumn{4}{|c|}{ Minor 2 Exam } & \multicolumn{4}{c|}{ Semester End Exam (SEE) } \\
\cline { 2 - 13 } & \multicolumn{2}{|c|}{ Q1b } & \multicolumn{2}{|c|}{ Q2b } & \multicolumn{2}{|c|}{ Q3b } & \multicolumn{2}{c|}{ Q4b } & \multicolumn{2}{|c|}{ Q5b } & \multicolumn{2}{|c|}{ Q6b } \\
\cline { 2 - 12 } & X & Y & X & Y & X & Y & X & Y & X & Y & X & Y \\
\hline $2016-17$ & 67 & 61.57 & 32 & 81.25 & 80 & 75.25 & 80 & 70.67 & 32 & 65.83 & 83 & 68.71 \\
\hline $2017-18$ & 80 & 61.72 & 51 & 81.81 & 72 & 71.79 & 83 & 51.55 & 30 & 68.57 & 90 & 80.77 \\
\hline
\end{tabular}

Note: $\mathrm{X}$ - number of students attempted, $\mathrm{Y}$ - percentage attainment

Table 6-Analysis of Feedback Questionnaire

\begin{tabular}{|c|c|c|c|c|c|c|c|}
\hline \multirow{2}{*}{$\begin{array}{c}\text { Feedback } \\
\text { Questions }\end{array}$} & \multicolumn{2}{|c|}{ Before } & \multicolumn{2}{c|}{ After } & \multirow{2}{*}{ p-value } & \multirow{2}{*}{$\begin{array}{c}\text { F } \\
\text { critical }\end{array}$} \\
\cline { 2 - 5 } & Mean & Variance & Mean & Variance & & & 4.13 \\
\hline Q1 & 6.05 & 4.58 & 8.2 & 2.17 & 0.000676 & 13.71 & 4.13 \\
\hline Q2 & 5.85 & 6.03 & 8.7 & 2.43 & $8.95 \mathrm{E}-05$ & 19.20 & 4.13 \\
\hline Q3 & 6.89 & 2.58 & 8.78 & 1.01 & 0.000165 & 17.93 & 4.13 \\
\hline Q4 & 7.79 & 2.62 & 8.74 & 1.65 & $\mathbf{0 . 0 5 3 2 4 3}$ & $\mathbf{3 . 9 9}$ & 4.13 \\
\hline Q5 & 6.15 & 3.61 & 7.5 & 0.68 & 0.005947 & 8.49 & 4.13 \\
\hline Q6 & 5.06 & 4.77 & 6.89 & 1.99 & 0.005101 & 8.97 & 4.13 \\
\hline Q7 & 7.37 & 1.58 & 8.74 & 1.65 & 0.002071 & 11.02 & 4.13 \\
\hline Q8 & 5.00 & 5.06 & 6.56 & 5.91 & $\mathbf{0 . 0 5 4 3 5 5}$ & $\mathbf{3 . 9 7}$ & 4.13 \\
\hline
\end{tabular}

The results obtained in year 2016-17 has reduced in SEE although the number of students' attempt is around $81 \%$. The 2017-18 batch students have fared well in SEE for the higher-level question. The number of attempts made by students in SEE in has improved by $17 \%$ compared to minor 2 exam.

\section{Discussion of Findings}

The results of the case study give indications about the influence of mixed learning styles in team-based learning. Some of the findings of this study are presented in this section. Learning preference of every individual student is known. $75 \%$ students of Section Aare predominantly active sometimes and reflective sometimes, whereas $50 \%$ of section B students were distributed in the moderate and strong preference towards active learning. The insight from this finding is that the active learners tend to like group work more than reflective learners, who prefer working alone [22][23].

It is also observed that there is a well-balanced learning preference of sequential and global learning styles with $80 \%$ students of section A; however, there is no correlation between the distributions of learning preferences of section $\mathrm{B}$ students. It is evident from the scores that $33 \%$ of 
students have a strong preference for sequential learning style which makes them rigid in following the step by step procedures and they become uncomfortable when a new situation arises. One of the reasons for this could be because of the huge percentage $(44 \%)$ of student strength having a different learning experience in the past educational setting

One more important observation done with respect to visual and verbal learning style, $97 \%$ of section $\mathrm{A}$ and $82 \%$ of $\mathrm{B}$ section are far more visual than verbal learners. With respect to sensing and intuitive learners, none of the section $\mathrm{A}$ students are strong sensory learners but $38 \%$ of B section students are strong learners who may rely too much on memorization and common and known methods and are hesitant in applying new techniques and innovative thinking [22][23]. It was also examined that the post-test scores are enhanced compared to pre-test which proves that conceptual understanding in students has improved.

\section{Student Feedback}

When course teacher interacted with students it was found that few teams wanted to form their teams on their own. The reason being told by students was unfamiliarity with group members and hence cannot communicate well. Few others gave positive comments about the group activities, including comments about augmenting the socialization, exposure to new ideas and better learning. Individual question wise statistical analysis using ANOVA test to assess the effectiveness of Control Systems Course Assignment is depicted in table 6 .

It is observed that the F value of $\mathrm{Q} 4$ and $\mathrm{Q} 8$ is less than $\mathrm{F}$ critical which means that students are on the verge of being capable to designing controller parameters for a given control system and the students confidence level is comparatively less in solving the controller design problem.

\section{Future Directions}

The present study focuses on forming teams using mixed learning styles however the following aspects could be considered for future work;

- Forming teams in one section using mixed learning styles and randomly forming teams in other section. This would allow for a comparison of the performance of teams formed with and without a strategy.

- The interaction between the dimensions of the learning styles preferences could also be considered to see how two learning styles when strategically combined impact the team performance and individual learning.

- Apart from learning styles preferences, other elements (grades, gender, etc) could also be taken into consideration in forming teams. This could give different dimensions to the team performance positively.

- The pre-test and post-test questions could be better framed to address the understanding levels of the concepts and the common misconceptions.

\section{Acknowledgement}

The authors would like to thank Prof. S.R.Karnik, Professor, Department of Electrical \& Electronics Engineering (EEE), KLE Technological University, Hubballi for helping and guiding us in successfully completing this work. We also thank Prof. A.B.Raju, Professor and Head of Department (EEE) for providing the necessary support to carry out this work. We would also like to thank our students for patiently listening to our instructions and completing the assignment.

\section{References}

1. Kriflik, Lynda, and Judy Mullan. "Strategies to Improve Student Reaction to Group Work." Journal of University Teaching and Learning Practice 4, no. 1 (2007): 13-27.

2. Deibel, Katherine. "Team formation methods for increasing interaction during in-class group work." In ACM SIGCSE Bulletin, vol. 37, no. 3, pp. 291-295. ACM, 2005.

3. Richards, Grant P and McNally, Helen A. "An Examination of Learning Styles and it's Impact on Curriculum Development", American Society for Engineering Education, 2011.

4. Lowe, Tony A., and Sean B. Brophy. "Understanding the impact of strategic team formation in early programming education." 2017.

5. Méndez, J. Albino, César Lorenzo, Leopoldo Acosta, Santiago Torres, and Evelio González. "A web-based tool for control engineering teaching." Computer Applications in Engineering Education 14, no. 3: 178187, 2006.

6. Chung, Gregory KWK, Thomas C. Harmon, and Eva L. Baker. "The impact of a simulation-based learning design project on student learning." IEEE Transactions on Education 44, no. 4 2001: 390-398, 2001.

7. Kittur Javeed. "Teaching Linear Control Systems: A Core Course in Electrical and Electronics Engineering." Journal of Engineering Education Transformations, 2016.

8. James, D. "Are Four Minds Better Than One? A Study on the Efficacy of Group Work." College and University, 80(3): 47-48, 2005.

9. Mahenthiran, S. and Rouse, P. "The impact of group selection on student performance and satisfaction." The International Journal of Educational Management, 14(6): 255-264, 2000.

10. Roberts, T., Ed. Online Collaborative Learning: Theory and Practice. Hershey, Information Science Publishing, 2004.

11. Rossin, D. and Hyland, T. "Group Work-based Learning within Higher Education: an integral ingredient for the personal and social development of students." Mentoring and Tutoring, 11(2): 153-162, 2003.

12. Chandrasekaran, Sivachandran, and Riyadh Al-Ameri. "Assessing team learning practices in project/design based learning approach." International Journal of Engineering Pedagogy (iJEP) 6, no. 3: 24-31, 2016.

13. L. Springer, M. E. Stanne, and S. S. Donovan. Effects of small-group learning on undergraduates in science, mathematics, engineering, and technology. Review of Educational Research, 69(1):21-51, 1999. 
14. R. M. Felder, G. N. Felder, and E. J. Dietz. A longitudinal study of engineering student performance and retention $\mathrm{v} / \mathrm{s}$ comparisons with traditionally-taught students. Journal of Engineering Education, 87(4):469480, 1998.

15. B. A. Soloman and R. M. Felder, "Index of Learning Styles Questionnaire,"

http://www.engr.ncsu.edu/learningstyles/ilsweb.html, accessed 2018.

16. Balamuralithara, B., and P. C. Woods. "Virtual laboratories in engineering education: The simulation lab and remote lab." Computer Applications in Engineering Education 17, no. 1: 108-118, 2009.

17. Lateef, Fatimah. "Simulation-based learning: Just like the real thing." Journal of Emergencies, Trauma and Shock 3, no. 4: 348. 2010.

18. Swaak, Janine, Wouter R. Van Joolingen, and Ton De Jong. "Supporting simulation-based learning; the effects of model progression and assignments on definitional and intuitive knowledge." Learning and instruction 8, no. 3: 235-252, 1998

19. Kittur, Javeed. "Enhancing the Controller Design skills in the course Linear Control Systems." Journal of Engineering Education Transformations, 2018.

20. Kolb, D.A.: The Kolb Learning Style Inventory. Boston: Hay Resources Direct, 1999.

21. Felder, R.M., Silverman, L.K.: Learning styles and teaching styles in engineering education. Eng. Education 78(7), 674-681, 1988.

22. Felder, Richard M., and Barbara A. Soloman. "Learning styles and strategies." At URL: http://www. engr. ncsu. edu/learningstyles/ilsweb. Html, 2000.

23. Hermon, J. P., and C. McCartan. "The use of learning styles as a guide for project group formation and methods of assessment." 2010.

24. Minal Salunke, Vijayalakshmi M, S.B. Burli "Collaborative Experiential Learning Model" Journal of Engineering Education Transformations, 2016.

25. Minal Salunke, Vijayalakshmi M "Enhancing teaching and learning for Basic Electrical Engineering course using simulation as a tool" Journal of Engineering Education Transformations, 2016.

\section{Appendix A \\ Assignment Question}

The modified Load-Frequency control model of an isolated power system area, to be operated with a controller $\left(\mathrm{G}_{\mathrm{C}}(\mathrm{s})\right)$ is considered.

It is now required to design suitable controller $\mathrm{G}_{\mathrm{c}}(\mathrm{s})$ and analyse the system performance. A part (not complete) of the assignment question is included here for reference for the readers.

A.

\section{Nichols tuning approach:}

Controller design using Zeigler-

(a) Determine Ultimate gain $\left(K_{\mathrm{cu}}\right)$ and Time constant $\left(T_{\mathrm{u}}\right)$ using $\mathrm{RH}$ criterion (b) Write a MATLAB code (in an m-file) to obtain the ROOT LOCUS diagram (using the command "rlocus"), and verify the values of $K_{\text {cuand }} T_{\mathrm{u}}$ obtained in part (a) above.

(c) Determine the controller parameters.

(d) Develop a MATLAB program of the system with controller and obtain the system performance under the following conditions:

d1. Unit step response with controller parameters found in part (c) above

d2. Unit step response with controller parameters after fine-tuning step-I

d3. Unit step response with controller parameters after fine-tuning step-II

d4. Unit step response with controller parameters after fine-tuning step-III

Prepare a report containing the following:

- Details of $K_{\text {cuand }} T_{\mathrm{u}}$ calculations using $\mathrm{RH}$ criterion $\{$ part (a) $\}$

- MATLAB file showing the commands used to obtain the root locus and the MATLAB figure of root locus diagram obtained $\{$ part (b) $\}$

- Computations of controller parameters \{part (c)\}

- MATLAB figures showing the unit step response comparisons of four cases (With original PID parameters, after first fine tuning, after second fine tuning and after third fine tuning) \{part (d)

- Comment on the system response pertaining to controller gain.

B. Controller design Pole-Placement Technique:

It is now required to design a as to place two dominant poles at ( controller so for PID, use integral gain $K_{\mathrm{i}}=$.

(a) Write a MATLAB code (in an m-file) to compute controller gains and to obtain the unit step response with a designed controller.

Add the following in the report:

- MATLAB file showing the commands used in the calculations of controller gains and unit step response

- MATLAB figure showing the unit step response.

- Comment on the system response pertaining to controller gains.

C. List atleast two applications controller is used 